\title{
Synapse-Associated Protein 97 Selectively Associates with a Subset of AMPA Receptors Early in their Biosynthetic Pathway
}

\author{
Nathalie Sans, Claudia Racca, Ronald S. Petralia, Ya-Xian Wang, Jennifer McCallum, and \\ Robert J. Wenthold \\ Laboratory of Neurochemistry, National Institute on Deafness and other Communication Disorders, National Institutes of \\ Health, Bethesda, Maryland 20892-8027
}

\begin{abstract}
The regulation of AMPA receptors at the postsynaptic membrane is a fundamental component of synaptic plasticity. In the hippocampus, the induction of long-term potentiation increases the delivery of GluR1, a major AMPA receptor subunit in hippocampal pyramidal neurons, to the synaptic plasma membrane through a mechanism that requires the PDZ binding domain of GluR1. Synapse-associated protein 97 (SAP97), a member of the membrane-associated guanylate kinase family, is believed to associate with AMPA receptors (AMPARs) containing the GluR1 subunit, but the functional significance of these interactions is unclear. We investigated the interaction of GluR1 with SAP97, the only PDZ protein known to interact with
\end{abstract}

Ionotropic glutamate receptors mediate most excitatory neurotransmission in the CNS. These receptors are concentrated at postsynaptic densities (PSDs) of excitatory synapses although a large population is also present in the cytoplasm of neuron somata and dendrites (Petralia, 1997). AMPA-type ionotropic glutamate receptors (AMPARs) include four subunits (GluR1-4) and form functional heteromeric or homomeric complexes of four or five subunits (Dingledine et al., 1999). GluR2 and GluR3 have a C-terminal PDZ-binding site (-SVKI) through which they can associate with PDZ domain-containing proteins such as glutamate receptor-interacting protein (GRIP), AMPAbinding protein (ABP), and PKC-interacting protein 1 (PICK1) (Dong et al., 1997; Srivastava et al., 1998; Wyszynski et al., 1999; Xia et al., 1999). The last four amino acids of the $\mathrm{C}$ terminus of GluR1 (-ATGL) interact with the PDZ domains of SAP97 (Leonard et al., 1998). Also, GluR2 interacts with $N$-ethylmaleimidesensitive factor (Nishimune et al., 1998; Osten et al., 1998; Song et al., 1998) and GluR1 with cytoskeletal protein 4.1 homologs (Shen et al., 2000a). These interacting proteins have been implicated in targeting and synaptic clustering of AMPARs, although the mechanisms involved are poorly understood. Native AMPARs, as heteromeric complexes, contain several potential inter-

\footnotetext{
Received May 9, 2001; revised June 20, 2001; accepted June 26, 2001.

This work was supported by the National Institute on Deafness and Other Communication Disorders intramural program. We thank Drs. J. Hell for antibodies to SAP97 and PSD-95 and P. Streit for antibodies to GluR1 and GluR2/3. We also thank Dr. A. Dosemeci for sharing the method for affinity purification of PSDs, G. P. Riordan and Dr. B. Kachar for assistance in using the Life Cell slam-freezing device for freezing unfixed tissue, Drs. C.-W. Ko and H. Hoffman for the statistical analysis of the EM results, and members of the laboratory of R. J. Wenthold for assistance in preparing and critical reading of this manuscript.

Correspondence should be addressed to Dr. Nathalie Sans, National Institute on Deafness and Other Communication Disorders, National Institutes of Health, Building 50, Room 4146, Bethesda, MD, 20892-8027. E-mail: sansn@nided.nih.gov. Copyright (ㄷ) 2001 Society for Neuroscience $0270-6474 / 01 / 217506-11 \$ 15.00 / 0$
}

GluR1. We find that interactions involving SAP97 and GluR1 occur early in the secretory pathway, while the receptors are in the endoplasmic reticulum or cis-Golgi. In contrast, few synaptic receptors associate with SAP97, suggesting that SAP97 dissociates from the receptor complex at the plasma membrane. We also show that internalization of GluR1, as triggered by NMDAR activation, does not require SAP97. These results implicate GluR1-SAP97 interactions in mechanisms underlying AMPA receptor targeting.

Key words: SAP97; GluR1; trafficking; ER-cis-Golgi; postsynaptic density; hippocampus

acting domains exposed to the cytoplasm. This raises the possibility of simultaneous, competing, or sequential interactions with other proteins.

Current evidence indicates that AMPAR trafficking plays a prominent role in regulating synaptic efficacy. The number and type of AMPARs present at the PSD can be rapidly altered by synaptic activity through endocytosis and exocytosis of receptors associated with the plasma membrane or intracellular membranes. Understanding the coordination between AMPAR trafficking events and the various known and unknown interacting proteins is key to understanding the regulation of synaptic function at excitatory synapses.

GluR1 is a major AMPAR subunit in hippocampal pyramidal neurons, and by expressing tagged green fluorescent proteinGluR1 subunits in pyramidal cells of hippocampal slices, it was shown that long-term potentiation (LTP) or increased activity of $\mathrm{Ca}^{2+} /$ calmodulin-dependent protein kinase II (CaMKII) increased delivery of GluR1 to synapses (Shi et al., 1999; Hayashi et al., 2000). This effect was diminished by mutating the PDZ interacting domain of GluR1, although this same mutation had no effect on basal synaptic transmission. Therefore, the interaction of GluR1 with a PDZ domain-containing protein may be critical for activityinduced increases in synaptic AMPARs but not required for constitutive addition of receptors. SAP97 may play a role in regulating AMPAR addition to hippocampal pyramidal cell synapses because it interacts with the C-terminal PDZ-interacting domain of GluR1 (Leonard et al., 1998). The report of this interaction initially appeared to have limited functional significance because SAP97 was earlier reported to be presynaptic (Müller et al., 1995), whereas GluR1 is predominantly postsynaptic (Petralia, 1997). However, it was recently shown that SAP97 is present at postsynaptic sites in cerebral cortex (Valtschanoff et al., 2000). In the present study we investigated the role of SAP97 in organizing 
and processing AMPARs in intact rat hippocampus. Although both biochemical and immunocytochemical results show that SAP97 is associated with the PSD, we find that most of the SAP97 is present in the cytoplasm and that it preferentially coimmunoprecipitates with immature AMPAR complexes. Our results support a model in which SAP97 associates with GluR1GluR2 containing AMPARs while they are in the endoplasmic reticulum-cis-Golgi (ER-CG), with SAP97 dissociating from the complex at the plasma membrane.

\section{MATERIALS AND METHODS}

Antibodies. The following primary antibodies were used for immunoprecipitation (IP), immunoblotting, and immunocytochemistry. Rabbit polyclonals to: SAP97 (JH62426, Sans et al., 2000; JH62428, Valtschanoff et al., 2000); SAP97 (PA1-066, PA1-741; Affinity BioReagents, Golden, CO); GluR1, GluR2/3, GluR3, and GluR4 (Wenthold et al., 1992); GluR2 (Petralia et al., 1997); PSD-95 (T60, JH62092; Sans et al., 2000); and calnexin (Rubio and Wenthold, 1999a). Mouse monoclonals to: GluR1 and GluR2-3 (Ottiger et al., 1995); NR1 (clone 54.1; PharMingen, San Diego, CA); NR2B, EEA1, and Rab4 (Transduction Laboratories, Lexington, KY), PSD-95 (7E1-1B8; Affinity BioReagents), synaptophysin and tubulin (Boehringer Mannheim, Indianapolis, IN); and BiP and Lamp 1 (StressGen, Victoria, British Columbia, Canada).

Preparation of membranes and subcellular fractionation. Total hippocampal membranes were obtained from postnatal day 35 (P35) Sprague Dawley rats by homogenizing in buffer A $[20 \mathrm{mM} \mathrm{HEPES,} \mathrm{pH}$ $7.4,150 \mathrm{~mm} \mathrm{NaCl}$, containing a cocktail of protease inhibitors $(2 \mathrm{~mm}$ EDTA, $1 \mathrm{~mm}$ 4-(2-aminoethyl)benzenesulfonyl fluoride hydrochloride (AEBSF), $50 \mu \mathrm{g} / \mathrm{ml}$ leupeptin, $10 \mu \mathrm{g} / \mathrm{ml}$ pepstatin, and $10 \mu \mathrm{g} / \mathrm{ml}$ aprotinin] and centrifugation $\left(14,000 \times g ; 30 \mathrm{~min} ; 4^{\circ} \mathrm{C}\right)$. Subcellular fractionation was performed following Gurd et al. (1974). Synaptic membranes (SMs) were prepared according to the procedure of Blackstone et al. (1992). Synaptic plasma membranes were recovered in the layer between 1.0 and $1.2 \mathrm{M}$ sucrose and resuspended in $\mathrm{PBS}, \mathrm{pH} 7.4$, with protease inhibitors or in buffer A as described above.

Immunoprecipitation. IP experiments were performed after Triton $\mathrm{X}-100$ solubilization as described previously (Blahos and Wenthold, 1996).

Deglycosylation. Membrane homogenates were either treated directly or were detergent solubilized and then incubated with SAP97 antiserum to immunoprecipitate SAP97 and associated AMPARs. Membranes or protein A-agarose pellets were resuspended in denaturing buffer $(10 \mathrm{mM}$ $\mathrm{NaH}_{2} \mathrm{PO}_{4}, \mathrm{pH} 6,0.5 \%$ SDS, $2 \%$ glycerol, and $1 \% \beta$-mercaptoethanol), incubated for $3 \mathrm{~min}$ at $100^{\circ} \mathrm{C}$, and diluted with $1 \%$ Nonidet P-40 in $10 \mathrm{~mm}$ $\mathrm{NaH}_{2} \mathrm{PO}_{4}, \mathrm{pH} 6$, containing the above protease inhibitor mixture, and incubated with endoglycosidase-H (Endo $\mathrm{H})(15 \mathrm{mU})$ or $N$-glycosidase $\mathrm{F}$ (PNGaseF) $(3 \mathrm{U})$ for $4 \mathrm{hr}$ at $37^{\circ} \mathrm{C}$. The resulting material was diluted with $5 \times$ sample buffer and subjected to SDS-PAGE on $8 \%$ acrylamide gels.

Magnetic bead fractionation. Magnetizable polystyrene beads coated with recombinant Protein A (Dynabeads Protein A; Dynal, Lake Success, NY) were used to isolate PSDs from the SM fraction. Beads were coated with PSD-95 antibodies [a combination of polyclonal (JH62092) and monoclonal (Affinity BioReagents) antibodies $(12 \mu \mathrm{g}$ of each antibody/100 $\mu$ l beads)] in $0.1 \mathrm{M} \mathrm{Na-phosphate,} \mathrm{pH} 8.1$, according to the manufacturer's suggestions, then washed and incubated with $250 \mu \mathrm{g}$ of $\mathrm{SM}$ for $1 \mathrm{hr}$ at $4^{\circ} \mathrm{C}$. After incubation, the beads were washed four times with $0.25 \mathrm{M}$ sucrose in PBS, pH 7.4, and either solubilized in protein sample buffer, subjected to SDS-PAGE and analyzed by Western blotting, or fixed in $4 \%$ paraformaldehyde (PFA) and $0.5 \%$ glutaraldehyde in $0.1 \mathrm{M}$ phosphate buffer (PB) for $30 \mathrm{~min}$, then $3 \times \mathrm{PBS}_{1} 1 \% \mathrm{OsO}_{4}$ in $\mathrm{PBS}$, $3 \times$ PBS, ethanol (10 min; 50, 75, 95, and $3 \times$ at $100 \%), 2 \times$ propylene oxide, propylene oxide:Epon (1:1 and 1:2 for $30 \mathrm{~min}$ each), overnight in Epon in vacuum, Epon in vacuum at $64^{\circ} \mathrm{C}$ for $24 \mathrm{hr}$, and stained with uranyl acetate and lead citrate.

SDS-PAGE and immunoblot analysis. Proteins were separated with SDS-PAGE (8 or 4-20\% gradient gels; Novex, San Diego, CA) and transferred to Immobilon-P membrane (Millipore, Bedford, MA) and treated as described in Sans et al. (2000). After chemiluminescence detection, films were scanned using a Molecular Dynamics (Sunnyvale, CA) densitometer.

Neuron cultures. Hippocampal or cortical primary neurons were prepared as described (Standley et al., 2000) and were maintained in
DMEM-F-12 and 10\% FBS and N2 supplements or in NB-B27 (Life Technologies, Grand Island, NY). High-density cortical neurons were cultured in $60 \mathrm{~mm}$ dishes coated with poly-L-lysine.

Biotinylation of cell surface proteins. Cultured cortical neurons were biotinylated with NHS-SS-biotin (1 mg/ml; Pierce, Rockford, IL) as described (Mammen et al., 1997). Membranes were resuspended in buffer A $(600 \mu \mathrm{l} /$ plate $)$ and solubilized with either $2 \%$ Triton X-100 for $30 \mathrm{~min}$ at $37^{\circ} \mathrm{C}$ or $1 \% \mathrm{SDS}$, boiled $5 \mathrm{~min}$ and then adjusted to $1 \%$ Triton $\mathrm{X}-100$. Insoluble material was removed by centrif ugation, and the soluble fraction was immunoprecipitated using antibodies to SAP97. Biotinylated proteins were isolated with streptavidin agarose (Sigma, St. Louis, MO) (Huh and Wenthold, 1999). For the double IP, biotinylated AMPARs were purified, after SAP97 IP, by elution of the affinity column with 50 mM diethylamine, $\mathrm{pH} 11.5$, containing $0.05 \%$ (w/v) sodium deoxycholate. Four fractions of $0.5 \mathrm{ml}$ were collected and immediately quenched to neutral $\mathrm{pH}$ with $2 \mathrm{M}$ glycine. The eluted biotinylated AMPAR-containing fractions were pooled and applied to an anti-streptavidin antibody affinity column for $2 \mathrm{hr}$ at $4^{\circ} \mathrm{C}$ and processed as described above.

Immunocytochemistry. To label surface AMPARs, neurons (2 weeks in culture) were incubated live for $1 \mathrm{hr}$ with mouse GluR1-N antibody (1 $\mu \mathrm{g} / \mathrm{ml}$ ) at room temperature (RT) in $3 \%$ normal goat serum (NGS)-PBS, then $2 \times$ PBS, 4\% PFA-PBS (RT; $20 \mathrm{~min}$ ), 10\% NGS-PBS (1 hr), and Cy3 IgG (1:500; Jackson ImmunoResearch, West Grove, PA) in 3\% NGS-PBS (30 min). For double-labeling, neurons were then permeabilized with $0.1 \%$ Triton X-100-PBS, incubated with $10 \%$ NGS-0.1\% Triton X-100-PBS (1 hr), primary antibody [rabbit SAP97 (JH62428; $1: 100$ ) in $3 \%$ NGS and $0.1 \%$ Triton X-100-PBS (1 hr)], and secondary antibody (FITC; 1:500; Jackson ImmunoResearch) in 3\% NGS-0.1\% Triton X-100-PBS (30 min). For localization of internalized AMPARs with SAP97, neurons were incubated live $1 \mathrm{hr}$ with GluR1-N antibody at $\mathrm{RT}$ in growth medium before a 2 min application of control solution, 100 $\mu \mathrm{M}$ AMPA, and $50 \mu \mathrm{M}$ APV (to prevent NMDA receptor activation), or $20 \mu \mathrm{M}$ NMDA. Cells were then incubated for $10-15 \mathrm{~min}$ at $37^{\circ} \mathrm{C}$ in growth medium to allow receptor endocytosis and recycling and fixed in 4\% PFA (RT; $20 \mathrm{~min}$ ). Remaining surface GluR1-N antibody was blocked with unconjugated rabbit anti-mouse IgG (Jackson ImmunoResearch), and cells were permeabilized with $0.1 \%$ Triton X-100-PBS. Double-labeling was performed as above. For colocalization of GluR1 or SAP97 with BiP (1:200) and SAP97 with endosomal proteins [EEA1 (1:200), Rab4 (1:50), and Lamp1 (1:50)], neurons were fixed, permeabilized, and double-labeled as above. Coverslips were mounted with ProLong AntiFade Kit (Molecular Probes, Eugene, OR). Fluorescent images of the neurons were obtained using a confocal microscope (Zeiss) and processed with Adobe Photoshop.

Preembedding light microscope methods for immunofluorescence and immunoperoxidase labeling of rat brain have been described previously (Petralia and Wenthold, 1992; Petralia et al., 1997). SAP97 serum was used (1:200 for immunofluorescence; 1:100-1:200 for immunoperoxidase). In control sections, PBS was substituted for primary antibody, and labeling was absent. The postembedding method has been described (Petralia et al., 1997, 1999a; Petralia and Wenthold, 1999; Sans et al., 2000) and is modified from a previous study (Matsubara et al., 1996). Briefly, rats were anesthetized and perfused with $4 \%$ PFA plus $0.5 \%$ glutaraldehyde in $0.12 \mathrm{M}$ phosphate buffer. Sections were cryoprotected in $30 \%$ glycerol and frozen in liquid propane in a Leica electron microscopy (EM) CPC (Universal cryoworkstation) (Vienna, Austria), then processed in a Leica automatic freeze-substitution system (AFS). An unfixed tissue method also was used [Petralia et al., 1999b, 2001; based on a method of J. Moreira (Petralia and Wenthold, 1998)], to avoid potential artifacts of tissue fixation. Rats were anesthetized, and the brain tissue was removed and frozen in a Life Cell CF100 cryofixation unit (The Woodlands, TX) within $\sim 2$ min, then placed in the AFS and processed as above. Antibodies for single-labeling (10 nm gold) included SAP97 serum (JH62426; 1:50) and affinity-purified SAP97 (JH62426; $6 \mu \mathrm{g} / \mathrm{ml}$ ). $1 \%$ NGS-TBST was substituted for primary antibodies in controls. Double-labeling methods using antibodies made in the same species, and criteria for synapse identification and gold counting were described previously (Petralia et al., 1999a; Sans et al., 2000).

All experiments were performed in accordance with the National Institutes of Health (NIH) Guide for the Care and Use of Laboratory Animals (NIH publication number 85-23) under protocol number 874-98. 
A
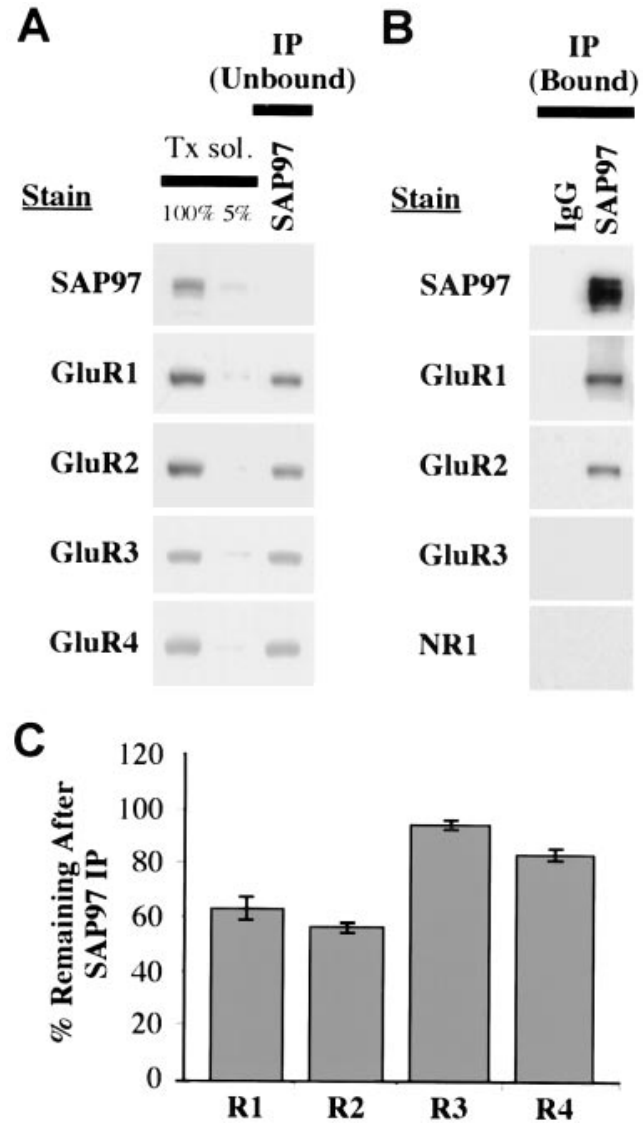

Figure 1. Co-immunoprecipitation of AMPAR subunits with SAP97 in rat hippocampus. Proteins were solubilized in 1\% Triton X-100, and SAP97 was immunoprecipitated using anti-SAP97 antibodies. A, AMPAR subunits remaining (unbound fraction) after IP of SAP97 from hippocampus homogenate with SAP97 antibodies. The two left lanes of each panel show the non-immunoprecipitated Triton-solubilized fraction (Tx sol). The $100 \%$ lane represents $10 \mu \mathrm{l}$ of sample applied, whereas the $5 \%$ lane represents $0.5 \mu \mathrm{l}$ applied (after 1:10 dilution with sample buffer). These lanes represent the range of labeling for quantification of immunoreactivity in the depleted fractions. For each gel, standards of 75, 50, 25, and $10 \%$ of the solubilized fraction were also analyzed (data not shown). To determine the amount of immunoprecipitated proteins, $10 \mu \mathrm{l}$ of the depleted fraction was analyzed, equivalent to an equal volume of the solubilized fraction (100\%). B, IP of AMPAR subunits (bound fraction) using anti-SAP97 antibodies. Ten microliters of bound immunoprecipitate fractions were separated by SDS-PAGE, immunoblotted, and incubated with antibodies against SAP97, GluR1, GluR2, GluR3, and NR1. C, Percentage of immunostaining remaining in the depleted fractions is shown on the graph (mean \pm SEM of three separate experiments).

\section{RESULTS}

\section{SAP97 is associated with a subset of AMPARs in hippocampus}

Co-IP of native proteins was used to establish that SAP97 interacts with AMPARs in the hippocampus. With 1\% Triton X-100, $82 \pm 5 \%$ of SAP97 was solubilized (data not shown), which is similar to the degree of AMPAR subunit solubilization in hippocampus using this detergent (Wenthold et al., 1996). With antibodies to SAP97, IP of SAP97 was $\sim 100 \%$ (Fig. $1 A$ ). SAP97 antibodies immunoprecipitated a portion of GluR1 and GluR2 but almost no GluR3 (Fig. $1 B$ ) and only a small amount of GluR4. By quantifying subunits remaining in the unbound fraction, we find that the following amounts of subunits coimmunoprecipitate with SAP97: GluR1, 36\%; GluR2, 44\%;
GluR3, 5\%; and GluR4, 17\% (Fig. 1C). Because SAP97 interacts directly with GluR1 only (Leonard et al., 1998), co-IP of other subunits, particularly GluR2, presumably indicates that they are present as complexes with GluR1. These results are consistent with previous findings showing that AMPARs in hippocampus are largely of two types, GluR1-GluR2 and GluR2-GluR3 (Wenthold et al., 1996). Controls showed no co-IP of AMPAR subunits with PSD-95 or SAP102 (data not shown), and NR1 did not co-immunoprecipitate with SAP97 in $1 \%$ Triton X-100soluble extract (Fig. $1 B$ ) as shown previously with deoxycholate soluble extracts (Sans et al., 2000).

\section{SAP97 is associated with immature GluR1 and GluR2}

Our IP results indicated that SAP97 is associated with only a subset of GluR1 and GluR2, but the results do not differentiate between a temporal or spatial subset. Because SAP97 may serve as an anchor to the PSD, the most likely explanation is that only synaptic AMPARs are associated with SAP97. The percentage of GluR1 and GluR2 associated with SAP97 is approximately similar to the percentage of AMPARs on the cell surface of cultured neurons (Hall and Soderling, 1997). However, PDZ proteins have been shown to interact with ion channel subunits earlier in their biosynthesis. A PDZ protein interacts with the NR1 subunit while it is in the ER-CG (Standley et al., 2000), and SAP97 interacts with newly synthesized Kv1 channels in transfected COS cells (Tiffany et al., 2000), raising the possibility of a role for SAP97 in AMPAR processing before insertion of receptors into the plasma membrane. In the biosynthesis of many glycoproteins, there is an intermediate stage in which the protein contains N-linked highmannose carbohydrates while trafficking through the ER-CG. Glycoproteins associated with ER-CG can be identified by their sensitivity to Endo-H, which specifically cleaves high mannose carbohydrates. Membrane homogenates of hippocampus were analyzed by Western blotting after denaturation and treatment with Endo-H or PNGaseF, which enzymatically removes all $\mathrm{N}$-linked carbohydrates. Treatment with Endo-H showed that all four subunits are to some extent Endo-H-sensitive. This was particularly apparent for GluR2, which contained a small EndoH-sensitive population that comigrated with completely deglycosylated protein obtained by treating with PNGaseF (Fig. 2A). For the other subunits, the same treatment resulted in the appearance of lower molecular weight bands that migrate at intermediate positions as well as a small proportion that migrated at the level of the completely deglycosylated subunit (data not shown). The partial Endo-H resistance is indicative of differential processing of multiple glycosylation sites on the molecule (Standley et al., 1998).

The GluR1 and GluR2 associated with SAP97 contained both Endo-H-sensitive and -insensitive forms of the receptor, but the Endo-H-sensitive form was substantially enriched compared with that found in total homogenate (Fig. $2 A$ ). These results suggest that SAP97 is preferentially associated with AMPARs that are incompletely glycosylated and localized to ER-CG. Because Endo-H-sensitive GluR2 is co-immunoprecipitated with SAP97, subunit assembly has at least partially occurred when SAP97 is linked to GluR1. Deglycosylation was completed while the receptor was linked to beads used to immunoprecipitate SAP97. To verify that these conditions alone were not responsible for the different Endo-H effects, we did a corresponding control in which AMPARs were linked to beads using antibodies to $\mathrm{C}$ termini. Treatment with Endo-H under these conditions gave the same results as treating an entire homogenate (data not shown). 
A

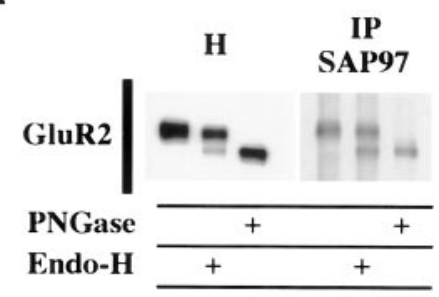

B

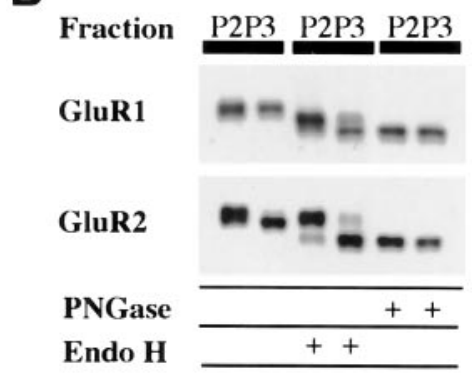

C

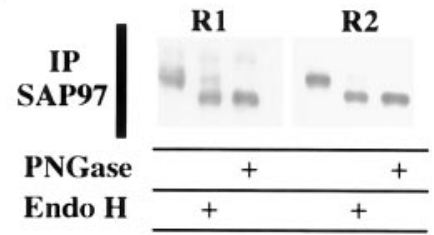

Figure 2. SAP97 is associated with immature GluR1 and GluR2. A, Glycosylation state of SAP97-associated AMPARs. Left, Membrane homogenates $(H)$ from hippocampus were solubilized with $0.5 \%$ SDS in the presence of $1 \% \beta$-mercaptoethanol. After dilution with $1 \%$ NP-40, soluble extracts were incubated in the absence of enzyme (control samples) or in the presence of Endo-H or PNGaseF. GluR2 has a small, but distinct, population that is Endo-H-sensitive. Right, Triton-solubilized AMPARs were first immunoprecipitated with SAP97 and then deglycosylated with Endo-H or PNGaseF. Equal amounts of sample were treated and subjected to SDS-PAGE. Although SAP97 immunoprecipitated both Endo$\mathrm{H}$-sensitive and Endo-H-insensitive GluR2, there is a substantial relative increase in the Endo-H-sensitive component showing that SAP97 preferentially associates with immature AMPARs. $B$, Glycosylation state of the crude synaptic membrane $(P 2)$ and microsomal $(P 3)$ fraction. The P3 fraction is enriched in Endo-H-sensitive GluR1 and GluR2. P2 and P3 fractions of hippocampus were treated with Endo-H or PNGaseF and analyzed by SDS-PAGE and Western blotting. $C$, Glycosylation state of SAP97-associated AMPARs. Almost all SAP97-associated GluR1 and GluR2 in the P3 fraction is Endo-H-sensitive.

A preparation enriched in ER and other intracellular membranes can be obtained by subfractionation. Subfractionating the hippocampus into P3 (microsomes) and P2 (crude synaptic membranes) shows that a much greater proportion of both GluR1 and GluR2 is Endo-H-sensitive in P3 compared with P2 (Fig. 2B). IP of SAP97 from the P3 fraction shows that most of the co-immunoprecipitating GluR1 and GluR2 is Endo-Hsensitive (Fig. 2C).

\section{AMPARs associated with SAP97 are concentrated in intracellular membranes}

Our results on Endo-H sensitivity suggested that a large amount of SAP97-associated AMPARs resides in ER-CG. To further investigate the subcellular distribution of this population, adult rat hippocampus was subfractionated into P3, P2, and SMs. Western blots (Fig. 3A) showed that SAP97 and AMPARs are present
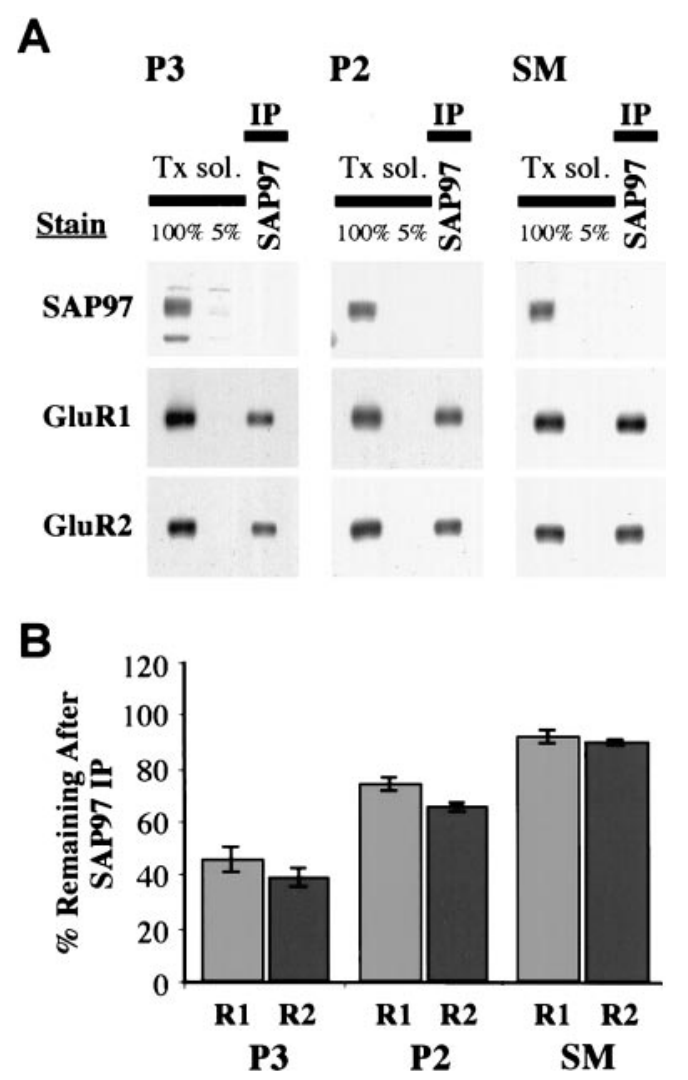

Figure 3. AMPARs associated with SAP97 are concentrated in intracellular membranes. The hippocampus was subfractionated into crude synaptic membrane $(P 2)$ and microsomal $(P 3)$ fraction and synaptic membrane $(S M)$. Triton-solubilized subfractions were immunoprecipitated with anti-SAP97 antibodies. $A$, GluR1 and GluR2 remaining (unbound fraction) after IP. $B$, Quantitation of immunostaining remaining in the depleted fractions (mean \pm SEM of three separate experiments) shows little SAP97-associated GluR1 and GluR2 in the SM fraction.

in all three fractions. However, solubilization followed by IP with SAP97 showed that SAP97-associated GluR1 and GluR2 is enriched in the microsome fraction. We found that $54 \%$ of GluR1 and $61 \%$ of GluR2 were co-immunoprecipitated by SAP97 in the P3 fraction, 26\% of GluR1 and 35\% of GluR2 in the P2 fraction, and only $9 \%$ of GluR 1 and $11 \%$ of GluR 2 in the SM fraction (Fig. $3 B)$. This represents a significant decrease in the percentage of AMPARs associated with SAP97 in the synaptic compartment versus the intracellular one.

Interestingly, the SM fraction contained a relatively high amount of SAP97 in addition to AMPARs, yet the amount of SAP97 linked to AMPARs was low, indicating that the SAP97 present in the SM fraction was not associated with AMPARs. Subfractionation based on gradient and differential centrif ugation is not quantitative, and substantial contamination by other membrane fractions can occur. Furthermore, the SM fraction contains presynaptic as well as postsynaptic membranes, and SAP97 has been reported to be presynaptic (Müller et al., 1995). To eliminate the possibility that the SAP97 present in the SM fraction is presynaptic, it would be useful to isolate PSDs. The PSD fraction can be obtained in a relatively pure form, based on its molecular composition and ultrastructural characteristics, but traditional PSD preparations require detergent extraction. We find that the bulk of SAP97, as well as AMPARs, is detergent-soluble, making this approach unusable for assessing SAP97 in the PSD fraction. 
To circumvent this limitation and to determine whether SAP97 is present in PSDs and associated with AMPARs, we used an affinity isolation method using magnetic beads coated with PSD-95 antibodies. PSD-95 is highly enriched in PSD with little associated with intracellular and presynaptic membranes (Cho et al., 1992). The PSD isolated with anti-PSD-95 beads were analyzed by SDS-PAGE and Western blotting or analyzed directly by EM. Ultrastructural analysis of the fraction verifies that it is enriched in PSDs with accompanying plasma membrane (Fig. $4 A$ ). Biochemical analysis shows that the PSD-95 isolated fraction is enriched in AMPARs and NMDARs but contains substantially less SAP97 than found in the SM (Fig. 4B). This fraction contains relatively little ER-CG and presynaptic vesicles based on the absence of markers for these organelles.

\section{Light and electron microscopy immunocytochemistry support both synaptic and intracellular localizations of SAP97}

Our biochemical results suggested that SAP97 is present both at synapses and in cytoplasm, but unlike PSD-95, which is concentrated in PSDs, SAP97 is predominantly cytoplasmic. To verify this and to determine whether SAP97 is uniformly distributed at all postsynaptic sites or concentrated at a subpopulation of synapses, the distribution of SAP97 was determined on sections of P35 rat hippocampus with immunofluorescence, immunoperoxidase, and immunogold techniques. Labeling was found throughout the cytoplasm in cell bodies and dendrites in the CA1 region, as seen with immunofluorescence and immunoperoxidase (Fig. $5 A$ ). With postembedding immunogold, SAP97 was found associated with PSDs as well as in cytoplasm and decorated cisternae of the ER (Fig. 5Bh), as shown by Aoki et al. (2001) in the rat visual cortex. In double-labeling experiments using two sizes of immunogold particles, SAP97 could be found colocalized with both GluR1 and GluR2-3 at synapses (Fig. 5Ba-d,j,k) and in clusters in cytoplasm (Fig. 5Be-g,i,l,m). These clusters of gold particles were typically associated with presumptive vesicular or tubulovesicular structures and ER cisternae (Rubio and Wenthold, 1999b; Aoki et al., 2001). In general, synaptic labeling was low, and most synapses appeared unlabeled. The apparent absence of labeling at synapses may indicate either a true absence or small amount of SAP97 or a statistical phenomenon. To address this, we optimized immunolabeling by using $5 \mathrm{~nm}$ gold secondary antibody and analyzed the labeling pattern at 204 synapses. Our results show that most synapses are unlabeled (28\% labeled; 0.6 gold per synapse and 2.1 gold per labeled synapse). Of the labeled synapses, most have a single gold particle, but a subset of synapses are heavily labeled with three or more gold particles (Fig. 5C), suggesting that a small population of synapses contains a high level of SAP97.

\section{SAP97 rarely colocalizes with surface expressed GluR1 and does not localize to AMPAR degradation and recycling pathways}

To investigate the relationship of SAP97 with AMPARs expressed at the surface of neurons, we examined the distribution of SAP97 and surface-expressed GluR1 in cultured hippocampal neurons (Fig. 6). Immunofluorescence techniques were used to surface label live neurons for GluR1 (red), followed by fixation and permeabilization to detect the intracellular SAP97 (green). In general, we observed that the SAP97 labeling is diffuse in the somatic cytoplasm of cultured neurons (data not shown) and becomes more punctate within dendrites. Proximal dendrites showed both diffuse and punctate labeling (Fig. 6C, NMDA cen-

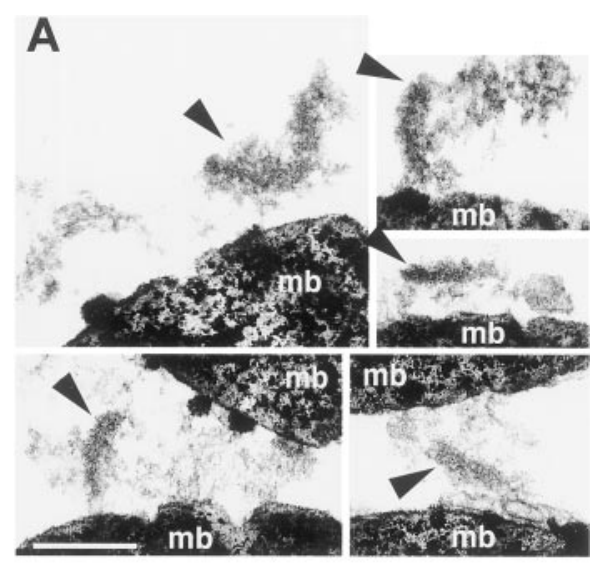

B

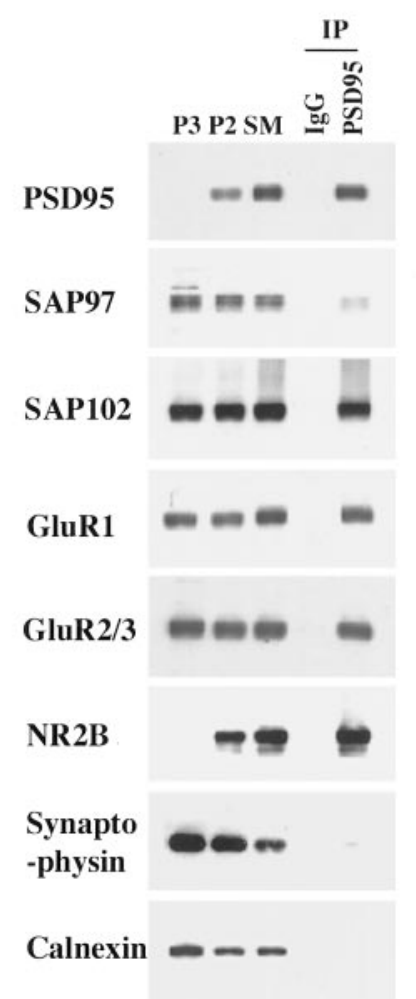

Figure 4. Isolation of PSD from the SM fraction using magnetic beads coated with antibodies to PSD-95. PSD were immunoisolated in the absence of detergent as described. $A$, Electron micrograph showing PSD (arrowheads) binding to magnetic beads $(\mathrm{mb})$. Scale bar, $0.2 \mu \mathrm{m}$. B, Distribution of SAP97 and proteins associated with the PSD (PSD-95, SAP102, GluR1, GluR2-3, NR2B), synaptic vesicles (synaptophysin), and ER (calnexin). IgG refers to a control in which magnetic beads were coated with rabbit IgG. For P3, P2, and SM, $10 \mu \mathrm{g}$ of protein was applied to each lane. Protein was not quantified in the immunoisolated fraction, but the same volume of sample was applied for each immunoblot.

tral panel, $D)$, whereas distal dendrites or dendrites of smaller caliber showed a punctate staining (Fig. 6A). Although SAP97 is present within the dendritic cytoplasm as well as somata of cultured neurons (data not shown), it appears to colocalize with GluR1 expressed at the surface of neurons very rarely (Fig. 6A). Furthermore, SAP97 and GluR1 partially colocalize with ER compartments within the somata (data not shown) as well as within dendrites, as shown by the colocalization with BiP, a chaperone protein residing in the ER (Fig. 6B). To further determine whether SAP97 is involved in degradation and recy- 


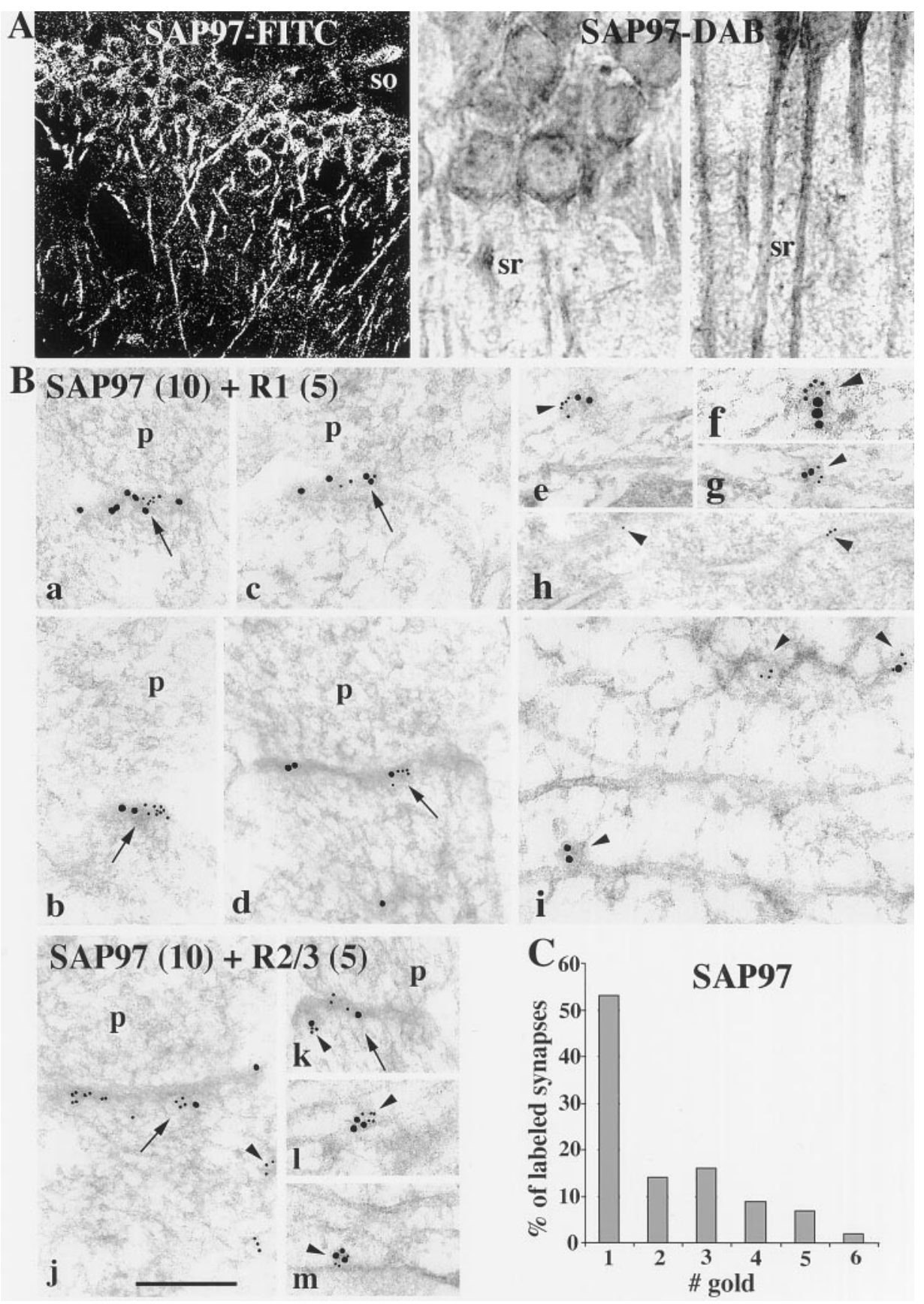

Figure 5. GluRs from hippocampus and distribution of SAP97 in the CA1 region using light $(A)$ and electron $(B, C)$ microscopy. $A$, With light microscopy (immunofluorescenceFITC and immunoperoxidase-DAB), labeling is found throughout the cell body, apical dendrites, and neuropil in strata oriens (so), pyramidale, and radiatum $(s r) . B, \mathrm{EM}(a-m)$, colocalization of SAP97 (10 nm gold) with GluR1 $(5 \mathrm{~nm}$ gold; $a-g, i)$ and GluR2-3 (5 nm gold: $j-m)$ and immunolabeling for SAP97 $(10 \mathrm{~nm}$ gold; $h)$ in fixed $(h)$ and unfixed $(a-g, i-m)$ sections of the stratum pyramidale and radiatum of the CA1 region of the hippocampus, respectively. $h$, Arrowheads indicate gold particles decorating ER cisternae in the soma of a pyramidal neuron. $a-g, i-m$, Arrows indicate colocalization of SAP97 and AMPARs at synapses. Arrowheads indicate presumptive cytoplasmic vesicular or tubulovesicular structures that are double- or single-labeled. These labeled structures are common in dendrites $(e-g$, $i, l, m)$ but also are seen in postsynaptic spines $(j, k)$. Three labeled vesicle-like structures are seen in $i$, one double-labeled and one each labeled with either 5 or $10 \mathrm{~nm}$ gold. $p$, Presynaptic terminal. Scale bar: $a-g, i-m, 0.2 \mu \mathrm{m} ; h$, $0.4 \mu \mathrm{m}$. $C$, Histogram showing immunogold labeling for SAP97 (5 nm gold; stratum radiatum; fixed section), representing $28 \%$ of the total synapses. Although zero and one counts are dominant, there seems to be a great deal of unobserved heterogeneity. This leads to overdispersion (highly significant; $p<0.0001$ ); that is, the actual variance exceeds the nominal Poisson variance. These results are consistent with there being a higher density of SAP97 in some synapses. cling pathways of surface-expressed AMPARs, we performed GluR1 internalization experiments (Beattie et al., 2000; Ehlers, 2000; Lin et al., 2000). Internalization of GluR1 was stimulated with application of control solution, AMPA and APV, or NMDA as in Ehlers (2000). Regardless of the agonist used, internalized GluR1 (red) accumulated in puncta along dendrites and within somata of neurons. SAP97 (green) also showed a punctate distribution within the same cellular compartments. Nonetheless, GluR1 puncta corresponding to endocytosed AMPARs seldom labeled for SAP97 (Fig. 6C). Recently it has been shown that internalized GluR1 localizes to early and late endosomes (Ehlers, 2000; Lin et al., 2000). To determine whether SAP97 is also present in these compartments, internalization was induced, and neurons were double-labeled for specific markers for early/recycling endosomes (EEA1 and Rab4) or late endosomes (Lamp1) and SAP97. Figure $6 D$ shows that, irrespective of agonist, SAP97 (green) does not colocalize with any of these markers (red). Thus, SAP97 rarely colocalizes with GluR1 expressed at the plasma membrane or after internalization and does not label membranous elements of degradation and recycling pathways used by GluR1.

\section{Some surface AMPARs are associated with SAP97 in cortical cultures}

Although SAP97 is much reduced in affinity-purified SM-PSDs, some AMPARs were co-immunoprecipitated with SAP97 in the SM fraction. Furthermore, EM studies on cerebral cortex (Valtschanoff et al., 2000) and hippocampus (this study) show that SAP97 is found in the PSD. To investigate further the relationship between AMPARs on the surface of neurons and SAP97, we 

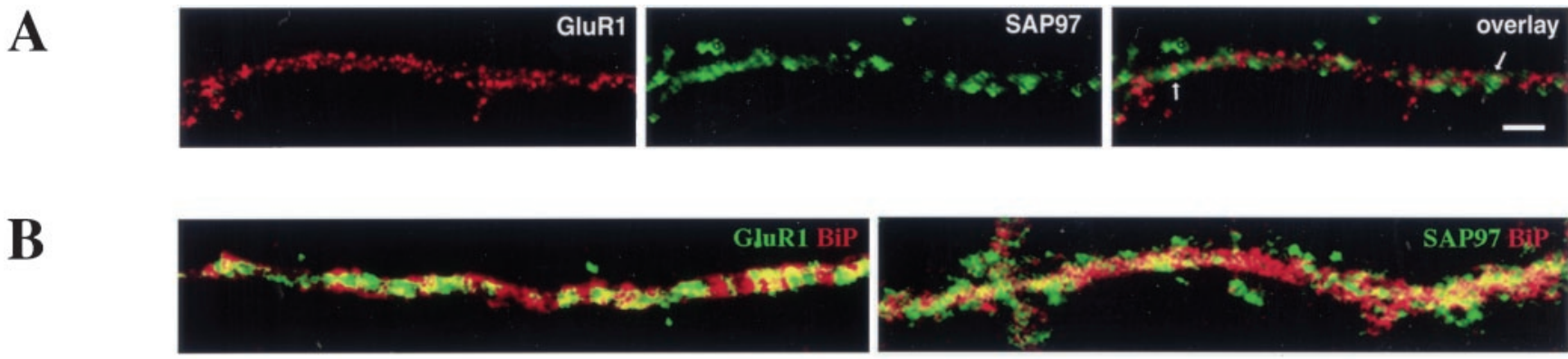

\section{C}
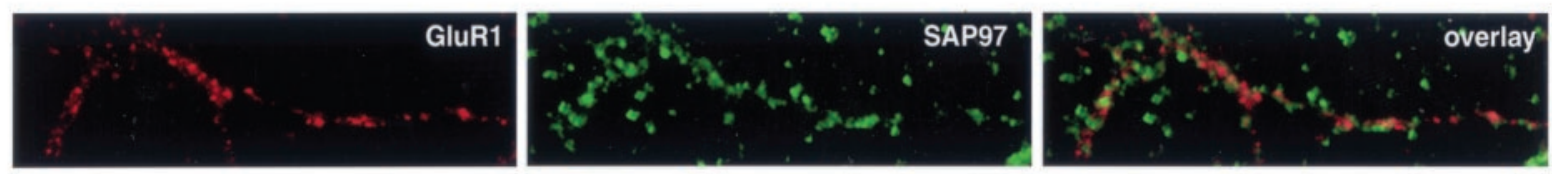

NMDA
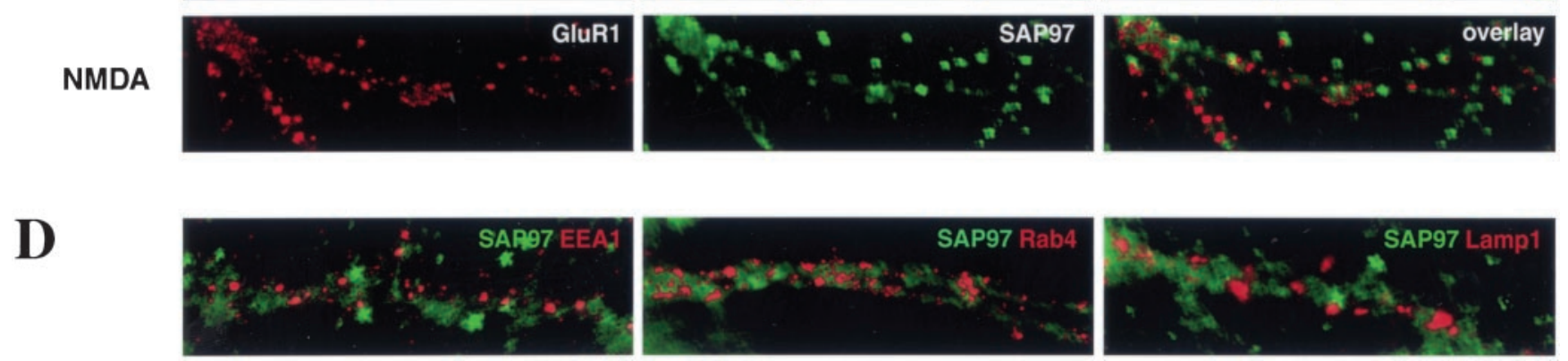

Figure 6. SAP97 is colocalized with a subpopulation of surface GluR1 in cultured hippocampal neurons. $A$, Live cultured hippocampal neurons were surface-labeled with antibodies to the GluR1-N and subsequently double-labeled for SAP97. Surface GluR1 forms clusters distributed throughout the dendritic tree (red). SAP97 immunofluorescence ( green) was observed along dendrites and in the soma and showed a more diff use pattern of distribution than GluR1 along dendrites. SAP97 labeling rarely overlapped with AMPAR labeling (arrows). B, Dendritic distribution of GluR1 ( green) and BiP (red) (right panel) and SAP97 (green) and BiP (left panel). Both GluR1 and SAP97 showed partial colocalization (yellow) with BiP, an ER marker, within dendrites. $C$, Live neurons were prelabeled with antibodies to GluR1-N, stimulated with $100 \mu \mathrm{M}$ AMPA and $50 \mu \mathrm{M}$ APV, or $20 \mu \mathrm{M}$ NMDA, returned to growth medium for $10-15 \mathrm{~min}$ at $37^{\circ} \mathrm{C}$, and internalized GluR1 (red) was detected together with SAP97 ( green). Internalized GluR1 accumulated in puncta along dendrites. SAP97 labeling is also punctate, but SAP97 and internalized GluR1 very rarely colocalize. $D$, Stimulated neurons were double-immunolabeled for SAP97 (green) and early/recycling endosomes (EEA1 and Rab4) and late endosomes (Lamp1) (red). Under all stimulation conditions (control shown), labeling for endosomes was punctiform and observed within dendritic and somatic cytoplasm. The endosomal compartments showed no SAP97 labeling. Scale bar, $2 \mu \mathrm{m}$.

biotinylated surface AMPARs in cortical cultures. To preserve or disrupt protein-protein interactions, membranes were solubilized in Triton X-100 or SDS, respectively. Biotinylated solubilized proteins were bound to streptavidin agarose beads or were immunoprecipitated with SAP97 antibodies and evaluated by Western blot analysis. Co-IP analysis of biotinylated receptors indicated that there is an association between SAP97 and biotinylated proteins (Fig. 7A). SAP97 was detected in the Triton $\mathrm{X}-100$-solubilized preparation but not in the SDS preparation in which protein interactions are disrupted, indicating that SAP97 itself is not biotinylated but is included through an interaction with another protein. Moreover, we immunoprecipitated SAP97 complexes and probed for biotinylated proteins. SAP97 immunoprecipitated unbiotinylated AMPAR subunits along with biotinylated ones (Fig. 7B). A minor band stained with streptavidinHRP co-migrated with GluR1 and GluR2 (Fig. 7B, arrow). SAP97 does not associate with NMDARs, as shown by the lack of biotinylated NR1 co-immunoprecipitating with SAP97. However, neither of these two approaches proves that SAP97 is associated with surface AMPARs. In Figure $7 A$, SAP97 could be associated with an unknown biotinylated surface protein. In Figure $7 B$, the streptavidin-HRP-labeled band that co-migrates with GluR1 and GluR2 could be an unrelated biotinylated protein that migrates at the same position. To show that surface AMPARs are associated with SAP97, we did sequential purification first with SAP97 antibodies followed by streptavidin binding of the bound fraction. Staining of the double bound fraction with antibodies to GluR1 and GluR2 showed the presence of the AMPARs (Fig. 7C). We also analyzed the surface-biotinylated AMPAR subunits isolated with streptavidin. Treatment of the surface-biotinylated protein, isolated with streptavidin, with Endo-H had no effect on GluR2 subunits, showing that surface GluR2 subunits are Endo-Hresistant (Fig. 7D).

\section{DISCUSSION}

Regulation of number and type of AMPARs present at the postsynaptic membrane has emerged as one of the key issues in understanding the molecular mechanisms underlying the expression of LTP and long-term depression (LTD). In the hippocampus, induction of LTP increases delivery of GluR1, a major AMPAR subunit in hippocampal pyramidal neurons, to the synaptic plasma membrane through a mechanism that requires the PDZ binding domain of GluR1 (Shi et al., 1999; Hayashi et al., 2000). In the present study, we investigated the role of SAP97, the only protein known to interact with the GluR1 PDZ binding domain, in the biosynthesis and processing of AMPARs in the hippocampus. Our results show that SAP97 interacts with GluR1 early in the biosynthetic pathway of GluR1-containing receptors 
A
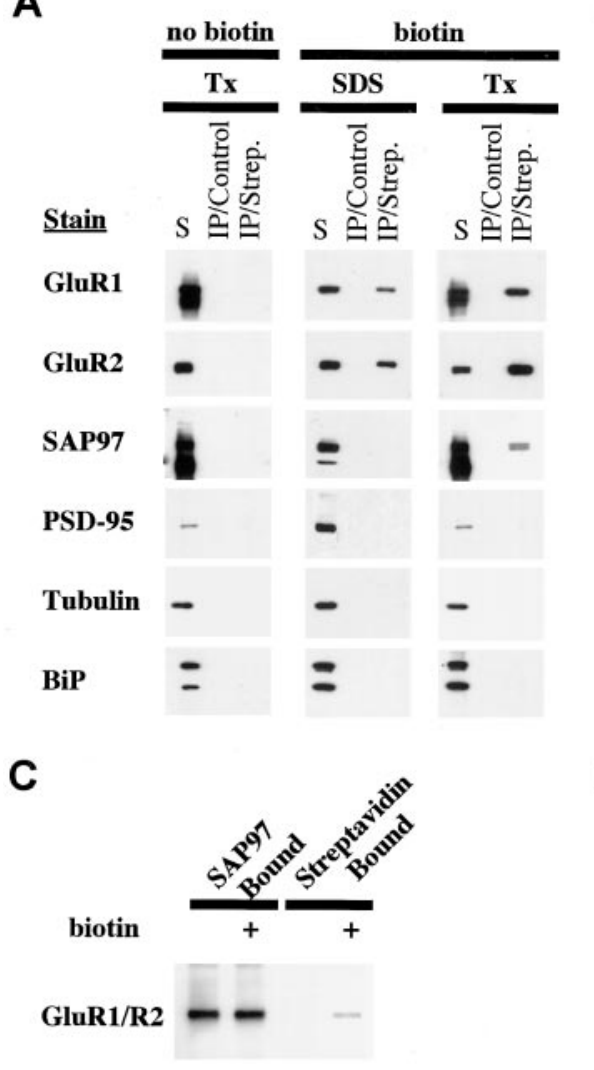

B

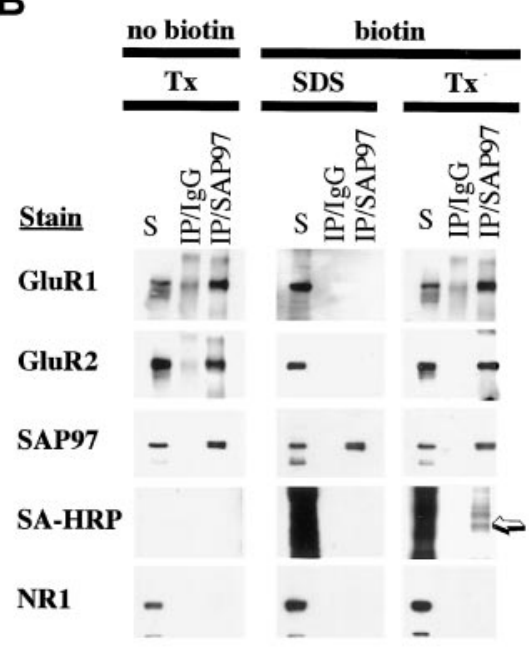

D

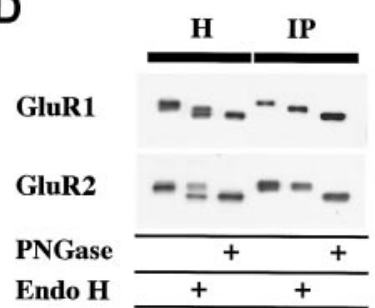

Figure 7. SAP97 is associated with some surface receptors in cultured cortical neurons. To determine if surface AMPARs are associated with SAP97, cortical cultures were biotinylated with NHS-SS-biotin, and presence of biotinylated AMPARs associated with SAP97 was assayed. Three experimental approaches were used to assess the relationship between SAP97 and biotinylated receptors. $A$, Two-week-old cortical cultures were biotinylated, and membranes were solubilized with $1 \%$ SDS (with boiling) or with $1 \%$ Triton $\mathrm{X}-100$. The detergent-soluble fraction was added to streptavidin-conjugated beads and incubated at $4^{\circ} \mathrm{C}$. Solubilized membranes $(S)$, IgG-precipitated (control), and streptavidin-precipitated proteins, were loaded so that each lane represents $1 \%$ of the material from the plate. The blots were probed with antibodies to GluR1, GluR2, SAP97, and PSD-95. BiP and tubulin antibodies were used as controls. The presence of SAP97 in the streptavidin fraction shows that some SAP97 is associated with biotinylated surface receptors. Note that this is seen only with Triton solubilization but not SDS solubilization, which disrupts protein-protein interactions. The absence of SAP97 in the SDS solubilized material is a control for biotinylation of intracellular proteins. Tubulin or BiP, an ER protein, are not biotinylated. $B$, Cultures of cortical neurons were biotinylated and membranes were solubilized with $1 \%$ SDS or with $1 \%$ Triton X-100. The detergent-soluble fraction was added to SAP97conjugated protein A and incubated at $4^{\circ} \mathrm{C}$. Solubilized membranes $(S)$, IgG-precipitated (control), and SAP97-precipitated proteins were loaded so that each lane represents $1 \%$ of the material from the plate. The blots were probed with GluR1, GluR2, SAP97, and NR1 antibodies, and with streptavidin-HRP. SAP97 immunoprecipitated unbiotinylated subunits along with biotinylated ones. In the streptavidin-HRP-stained panel, a band that co-migrates with GluR1 and GluR2 is seen (arrow). SAP97 did not associate with NMDARs. $C$, Co-migration of streptavidin-HRP with GluR1 and GluR2, as shown in $B$, does not prove that the biotinylated band is indeed GluR1-GluR2. To establish this, double affinity purification of biotinylated AMPARs by sequential anti-SAP97 and streptavidin IP was done. Cortical neurons were exposed to $1 \mathrm{mg} / \mathrm{ml} \mathrm{NHS}-\mathrm{SS}$-biotin or to PBS $-\mathrm{Ca}^{2+}-\mathrm{Mg}^{2+}$ (control) and processed as described. Lanes 1 and 2 , Anti-SAP97 immunoprecipitated GluRs; lanes 3 and 4, anti-SAP97 and streptavidin-precipitated GluRs. D, To show that Endo-H-sensitive receptors are not present on the cell surface, surface receptors immunoprecipitated with streptavidin-conjugated beads $(I P)$, were treated with Endo-H or PNGaseF and analyzed by SDS-PAGE and Western blotting. Treatment of surface-biotinylated protein with Endo-H has no effect on GluR1 or GluR2, showing that surface GluR2 are Endo-H-resistant. Total homogenates $(H)$ contain an Endo-H-sensitive component.

where it may play a role in maturation of receptor complexes in the ER-CG and delivery of receptors to synapses. However, at the SM, SAP97 is largely dissociated from AMPARs, suggesting that it does not play a major role in anchoring AMPARs at synapses.

\section{SAP97 is associated with intracellular AMPARs in the hippocampus}

SAP97 is a member of the membrane-associated guanylate kinase family that also includes PSD-95, PSD-93, and SAP102. Our biochemical and immunocytochemical analyses of the individual family members show two general patterns of distribution: PSD-95 and PSD-93 are highly concentrated at PSD, whereas SAP97 and SAP102, although found at synaptic densities, are abundant in the cytoplasm and associated with intracellular membranes (Sans et al., 2000; Standley et al., 2000). This distribution may be determined by palmitoylation sites, present at $\mathrm{N}$ termini of PSD-95 and PSD-93 but absent in SAP97 and SAP102. These sites may anchor receptors to the plasma membrane (El-Husseini et al., 2000). The intracellular localization of SAP102 and SAP97 is consistent with a role in intracellular organization of membrane proteins. We find that a subpopulation of AMPARs in the hippocampus co-immunoprecipitates with SAP97. These receptors are composed primarily of GluR1 and GluR2 and essentially no GluR3. This finding is consistent with previous results reveal- ing no apparent co-IP of GluR3 with GluR1 in the hippocampus and supports the conclusion that AMPARs in the hippocampus are primarily composed of GluR1-GluR2 and GluR2-GluR3 (Wenthold et al., 1996). Because SAP97 has been shown to interact with GluR1 only (Leonard et al., 1998), the coimmunoprecipitating GluR2 would be in a heteromeric complex with GluR1. Less than $50 \%$ of the GluR1 and GluR2 is coimmunoprecipitated with SAP97, and this population is enriched in immature receptor complexes, which are incompletely glycosylated.

The increasing number of examples of PDZ proteins interacting with ion channels at the level of the ER-CG suggests that this interaction may be an important part of a mechanism for regulating the distribution and surface expression of ion channels in neurons. Kv1 channels expressed in COS cells are present on the cell surface; however, coexpression with SAP97 resulted in ER retention of Kv1 and a block of surface expression (Tiffany et al., 2000). This effect is dependent on the PDZ interaction because the ER distribution of Kv1 is abolished after mutation of its $\mathrm{C}$ terminus. A PDZ interaction with NR1 splice variants has an opposite effect and abolishes ER retention and results in surface expression of the unassembled NR1 subunit (Standley et al., 2000). The effect of SAP97 on GluR1 distribution has been investigated in COS cells and expression of SAP97 inhibited 
surface expression of GluR1 (Shen et al., 2000b). ER retention is often associated with quality control and is used to ensure proper folding, subunit interaction, and stoichiometry. Because of the limitations in obtaining pure subcellular fractions, we cannot determine whether all GluR1 associates with SAP97 when it resides in the ER. However, the significant enrichment of SAP97associated GluR1 in P3, a fraction that contains ER but also a range of other intracellular membranes, indicates at least that most of the GluR1 interacts with SAP97. The fact that a significant part of the SAP97-associated AMPARs are Endo-Hinsensitive, showing that they have cleared the ER-CG, indicates that SAP97 has a role beyond the ER-CG. SAP97 is unlikely to play a dominant role in the dendritic targeting of GluR1. SAP97 is reported to be present both in axons and dendrites, so either SAP97 alone is not specifically targeted to one domain or its distribution is determined by the protein with which it is associated, in this case GluR1. The latter interpretation is consistent with results showing that the axonal localization of PSD-95 requires an interaction of Kv1.4 (Arnold and Clapham, 1999). This interpretation is also supported by data showing that the dendritic sorting of GluR1 is dependent on the proximal region of the $\mathrm{C}$ terminus, and this does not involve PDZ interactions (Ruberti and Dotti, 2000).

The presence of ER in dendrites raises the possibility that ER processing of membrane proteins destined for the postsynaptic membrane occurs in the dendrite. This would allow synaptic surface expression to be directly regulated by exit from the dendritic ER and, thus, associated proteins, such as SAP97, could directly regulate exit from the ER. However, we find a relatively small amount of Endo-H-sensitive GluR1 and GluR2 in the hippocampus. Therefore, if any AMPAR is associated with the dendritic ER-CG, it would account for a very small proportion of the pool of intracellular AMPARs found in dendrites. Regardless of where AMPARs are ER associated in neurons, the regulation of ER exit could be a critical step in receptor regulation by controlling the amount of receptor present in a pool available for surface expression. Because a significant fraction of SAP97associated receptor is Endo-H-insensitive and has passed through the ER-CG, our results suggest that SAP97-associated AMPARs are released from the ER-CG into an intracellular pool and that SAP97 remains associated with GluR1 in this pool. The presence of such a pool is supported by our EM immunogold results that show AMPARs in close proximity to SAP97 in dendrites.

\section{The role of SAP97 in the synaptic delivery of AMPARs}

Our data extend current models of AMPAR delivery to the SM (Fig. 8). Malinow et al. (2000) propose that AMPARs are trafficked in two different ways based on the composition of the receptor complex. Thus, receptors containing GluR1 are added only through a regulated pathway, whereas those without GluR1 are added through a constitutive pathway. In the hippocampus, GluR1-containing receptors are mostly heteromeric complexes of GluR1 and GluR2, whereas receptors without GluR1 are mostly heteromers of GluR2 and GluR3. We find that SAP97 associates with GluR1 while it is in the ER-CG and remains with the GluR1 during delivery to the dendrite. Our results suggest that with synaptic stimulation, the SAP97-AMPAR complex is delivered to the plasma membrane, whereupon the SAP97 soon dissociates from the receptor. Our observation that a small population of synapses has high levels of SAP97 would correspond to those synapses to which GluR1 has been delivered recently. The absence of SAP97 from most PSDs suggests that it is not primarily

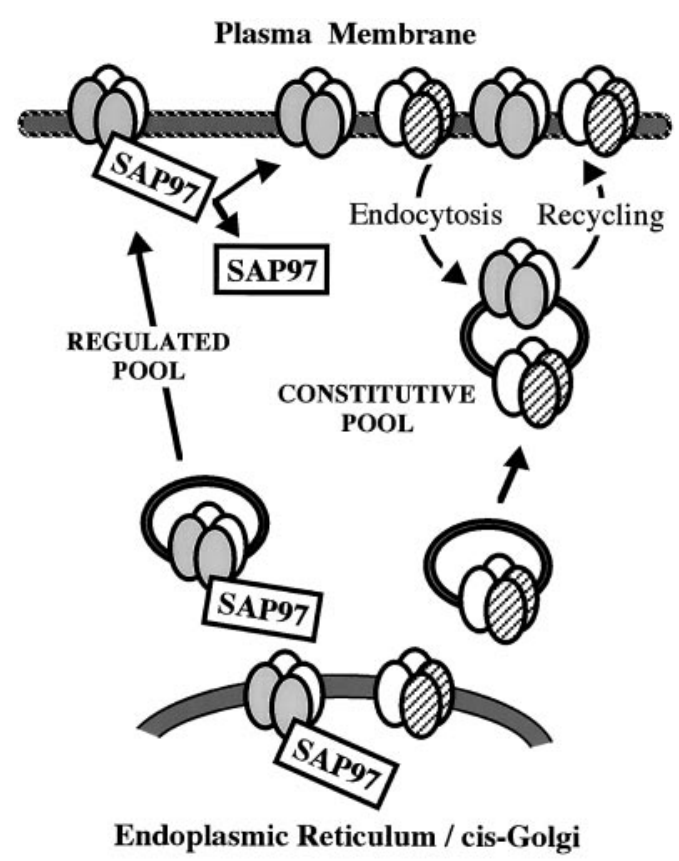

Figure 8. Model for the addition of AMPARs to the synaptic membrane. AMPARs with and without GluR1 are added to the SM following different pathways. The predominant AMPAR subunits in the adult hippocampus are GluR1 (shaded ovals), GluR2 (open ovals), and GluR3 (striped ovals). SAP97 is associated with GluR1 and plays a role only in initial delivery of receptors. After internalization, GluR1-containing complexes enter the constitutive receptor pool.

involved in anchoring the receptor complex at the postsynaptic membrane. This may be achieved by one of the other known interactors of AMPAR C termini, a yet unknown protein, or the AMPARs may not be firmly anchored, which would be consistent with the solubility of AMPARs in weak detergent, such as Triton X-100 (Wenthold et al., 1996).

A number of studies have now established that synaptic AMPARs are readily internalized following a variety of stimuli. This mechanism may partly control the number of receptors at the SM and may also regulate the composition of these receptors by selective internalization and re-insertion (Liu and Cull-Candy, 2000). Malinow et al. (2000) propose that receptors containing GluR1 are added only through a regulated pathway, whereas those without GluR1 are added through a constitutive pathway. Although it remains to be determined exactly when the regulated and constitutive pathways would be operative, limiting GluR1 addition to the regulated pathway, as the Malinow's model proposes, raises a number of questions. In the adult hippocampus, most synapses contain GluR1; if GluR1 is added only through the regulated pathway, it would indicate that most synapses have been recently activated or that GluR1 is a stable component of the synapse after it is added. Studies on the cerebellum and spinal cord cultures indicate that total and surface AMPARs have half-lives in the order of $1 \mathrm{~d}$ (Mammen et al., 1997; Huh and Wenthold, 1999). Studies on hippocampal cultures show that GluR1 is rapidly internalized and re-expressed on the surface (Beattie et al., 2000; Ehlers, 2000; Lin et al., 2000). Our data suggest that internalized GluR1 does not re-associate with SAP97. Because most GluR1 in the hippocampus is in a complex with GluR2, the internalized GluR1-GluR2 complex could now be transferred to the constitutive pathway and be controlled by proteins that interact with the GluR2 C terminus such as NSF and 
GRIP-ABP. A recent study has shown that GRIP may play a role in retaining internalized AMPARs in an intracellular store after induction of LTD (Daw et al., 2000). Such a mechanism would parallel a role for SAP97 in maintaining an intracellular store of newly synthesized GluR1. Our model would also provide a separate mechanism for trafficking homomeric GluR1 receptors. GluR1 homomeric complexes are relatively minor in the hippocampus overall ( $\sim 8 \%$ of the total AMPARs in the CA1-CA2) (Wenthold et al., 1996), but are much more abundant in some specific cell types. Although such complexes may be treated like heteromeric complexes during initial delivery to the synapse, after internalization, they would not enter the constitutive pathway because they lack the GluR2 C terminus. This would provide a mechanism to transiently supply calcium-permeable receptors to newly potentiated synapses that might increase $\mathrm{Ca}^{2+}$ entry during LTP.

\section{REFERENCES}

Aoki C, Miko I, Oviedo H, Mikeladze-Dvali T, Alexandre L, Sweeney N, Bredt DS (2001) Electron microscopic immunocytochemical detection of PSD-95, PSD-93, SAP102, and SAP97 at postsynaptic, presynaptic, and nonsynaptic sites of adult and neonatal rat visual cortex. Synapse 40:239-257.

Arnold DB, Clapham DE (1999) Molecular determinants for subcellular localization of PSD-95 with an interacting $\mathrm{K}+$ channel. Neuron 23:149-157.

Beattie EC, Carroll RC, Yu X, Morishita W, Yasuda H, von Zastrow M, Malenka RC (2000) Regulation of AMPA receptor endocytosis by a signaling mechanism shared with LTD. Nat Neurosci 3:1291-1300.

Blackstone CD, Levey AI, Martin LJ, Price DL, Huganir RL (1992) Immunological detection of glutamate receptor subtypes in human central nervous system. Annu Neurol 31:680-683.

Blahos IIJ, Wenthold RJ (1996) Relationship between NMDA receptor NR1 splice variants and NR2 subunits. J Biol Chem 271:15669-15674.

Cho K-O, Hunt CA, Kennedy MB (1992) The rat brain postsynaptic density fraction contains a homolog of the Drosophila disks-large tumor suppressor protein. Neuron 9:929-942.

Daw MI, Chittajallu R, Bortolotto ZA, Dev KK, Duprat F, Henley JM, Collingridge GL, Isaac JTR (2000) PDZ Proteins interacting with C-Terminal GluR2/3 are involved in a PKC-dependent regulation of AMPA receptors at hippocampal synapses. Neuron 28:873-886.

Dingledine R, Borges K, Bowie D, Traynelis SF (1999) The glutamate receptor ion channels. Pharmacol Rev 51:7-62.

Dong H, O'Brien RJ, Fung ET, Lanahan AA, Worley PF, Huganir RL (1997) GRIP: a synaptic PDZ domain-containing protein that interacts with AMPA receptors. Nature 386:279-284.

Ehlers MD (2000) Reinsertion or degradation of AMPA receptors determined by activity-dependent endocytic sorting. Neuron 28:511-525.

El-Husseini AE, Topinka JR, Lehrer-Graiwer JE, Firestein BL, Craven SE, Aoki C, Bredt DS (2000) Ion channel clustering by membraneassociated guanylate kinases. Differential regulation by $\mathrm{N}$-terminal lipid and metal binding motifs. J Biol Chem 275:23904-23910.

Gurd JW, Jones LR, Mahler HR, Moore WJ (1974) Isolation and partial characterization of rat brain synaptic plasma membranes. J Neurochem 22:281-290.

Hall RA, Soderling TR (1997) Differential surface expression and phosphorylation of the $N$-methyl-D-aspartate receptor subunits NR1 and NR2 in cultured hippocampal neurons. J Biol Chem 272:4135-4140.

Hayashi Y, Shi SH, Esteban JA, Poncer JC, Malinow R (2000) Driving AMPA receptors into synapses by LTP and CaMKII: requirement for GluR1 and PDZ domain interaction. Science 287:2262-2267.

Huh K-H, Wenthold RJ (1999) Turnover analysis of glutamate receptors identifies a rapidly degraded pool of the $N$-methyl-D-aspartate receptor subunit, NR1, in cultured cerebellar granule cells. J Biol Chem 274:151-157.

Leonard AS, Davare MA, Horne MC, Garner CC, Hell JW (1998) SAP97 is associated with the alpha-amino-3-hydroxy-5-methylisoxazole-4-propionic acid receptor GluR1 subunit. J Biol Chem 273: 19518-19524.

Lin JW, Ju W, Foster K, Lee SH, Ahmadian G, Wyszynski M, Wang YT, Sheng M (2000) Distinct molecular mechanisms and divergent endocytotic pathways of AMPA receptor internalization. Nat Neurosci 12:1282-1290.

Liu SQ, Cull-Candy SG (2000) Synaptic activity at calcium-permeable AMPA receptors induces a switch in receptor subtype. Nature 25:454458 .
Malinow R, Mainen ZF, Hayashim Y (2000) LTP mechanisms: from silence to four lane traffic. Curr Opin Neurobiol 10:352-357.

Mammen AL, Huganir RL, O’Brien RJ (1997) Redistribution and stabilization of cell surface glutamate receptors during synapse formation. J Neurosci 17:7351-7358.

Matsubara A, Laake JH, Davanger S, Usami S, Ottersen OP (1996) Organization of AMPA receptor subunits at a glutamate synapse: a quantitative immunogold analysis of hair cell synapses in the rat organ of Corti. J Neurosci 16:4457-4467.

Müller BM, Kistner U, Veh RW, Cases-Langhoff C, Becker B, Gundelfinger ED, Garner CC (1995) Molecular characterization and spatial distribution of SAP97, a novel presynaptic protein homologous to SAP90 and the Drosophila discs-large tumor suppressor protein. J Neurosci 15:2354-2366.

Nishimune A, Isaac JT, Molnar E, Noel J, Nash SR, Tagaya M, Collingridge GL, Nakanishi S, Henley JM (1998) NSF binding to GluR2 regulates synaptic transmission. Neuron 21:87-97.

Osten P, Srivastava S, Inman GJ, Vilim FS, Khatri L, Lee LM, States BA, Einheber S, Milner TA, Hanson PI, Ziff EB (1998) The AMPA receptor GluR2 C terminus can mediate a reversible, ATP-dependent interaction with NSF and alpha- and beta-SNAPs. Neuron 21:99-110.

Ottiger HP, Gerfin-Moser A, Del Principe F, Dutly F, Streit P (1995) Protein, nucleotide molecular cloning and differential expression patterns of avian glutamate receptor mRNAs. J Neurochem 64:2413-2426.

Petralia RS (1997) Immunocytochemical localization of ionotropic glutamate receptors (GluRs) in neural circuits. In: The ionotropic glutamate receptors, pp 219-263 (Monoghan DT, Wenthold RJ, eds). Totowa, NJ: Humana.

Petralia RS, Wenthold RJ (1992) Light and electron immunocytochemical localization of AMPA-selective glutamate receptors in the rat brain. J Comp Neurol 318:329-354.

Petralia RS, Wenthold RJ (1998) Glutamate receptors: synthetic peptides and histochemical analysis. In: Receptor localization: laboratory methods and procedures, pp 46-74 (Ariano MA, ed). New York: Wiley.

Petralia RS, Wenthold RJ (1999) Immunocytochemistry of NMDA receptors. Methods Mol Biol 128:73-92.

Petralia RS, Wang YX, Mayat E, Wenthold RJ (1997) Glutamate receptor subunit 2-selective antibody shows a differential distribution of calcium-impermeable AMPA receptors among populations of neurons. J Comp Neurol 385:456-476.

Petralia RS, Esteban JA, Wang Y-X, Partridge JG, Z hao H-M, Wenthold RJ, Malinow R (1999a) Selective acquisition of AMPA receptors at hippocampus CA1 synapses during postnatal development. Nat Neurosci 2:31-36.

Petralia RS, Wang Y-X, Sans N, Wenthold RJ (1999b) Organization of glutamate receptors and associated proteins in the postsynaptic spine. Soc Neurosci Abstr 25:1237.

Petralia RS, Wang Y-X, Sans N, Worley PF, Hammer III JA, Wenthold RJ (2001) Glutamate receptor targeting in the postsynaptic spine involves mechanisms that are independent of myosin Va. Eur J Neurosci 13:1722-1732.

Ruberti F, Dotti CG (2000) Involvement of the proximal C terminus of the AMPA receptor subunit GluR1 in dendritic sorting. J Neurosci 20:RC78.

Rubio ME, Wenthold RJ (1999a) Calnexin and the immunoglobulin binding protein (BiP) co-immunoprecipitate with AMPA receptors. J Neurochem 73:942-948.

Rubio ME, Wenthold RJ (1999b) Differential distribution of intracellular glutamate receptors in dendrites. J Neurosci 19:5549-5562.

Sans N, Petralia RS, Wang YX, Blahos J, Hell JW, Wenthold RJ (2000) A developmental change in NMDA receptor-associated proteins at hippocampal synapses. J Neurosci 20:1260-1271.

Shen L, Liang F, Walensky LD, Huganir RL (2000a) Regulation of AMPA receptor GluR1 subunit surface expression by a $4.1 \mathrm{~N}$-linked actin cytoskeletal association. J Neurosci 20:7932-7940.

Shen L, Liang F, Zhang X, Garner CC, Huganir RL (2000b) SAP97 is involved in controlling CaM KII mediated surface induction of AMPA receptor. Soc Neurosci Abstr 26:1131.

Shi SH, Hayashi Y, Petralia RS, Zaman SH, Wenthold RJ, Svoboda K, Malinow R (1999) Rapid spine delivery and redistribution of AMPA receptors after synaptic NMDA receptor activation. Science 284:1811-1816.

Song I, Kamboj S, Xia J, Dong H, Liao D, Huganir RL (1998) Interaction of the $N$-ethylmaleimide-sensitive factor with AMPA receptors. Neuron 21:393-400.

Srivastava S, Osten P, Vilim FS, Khatri L, Inman G, States B, Daly C, DeSouza S, Abagyan R, Valtschanoff JG, Weinberg RJ, Ziff EB (1998) Novel anchorage of GluR2/3 to the postsynaptic density by the AMPA receptor-binding protein ABP. Neuron 21:581-591. 
Standley S, Tocco G, Wagle N, Baudry M (1998) High- and low-affinity alpha- $\left[{ }^{3} \mathrm{H}\right]$ amino-3-hydroxy-5-methylisoxazole-4-propionic acid $\left(\left[{ }^{3} \mathrm{H}\right]-\right.$ AMPA) binding sites represent immature and mature forms of AMPA receptors and are composed of differentially glycosylated subunits. J Neurochem 70:2434-2445.

Standley S, Roche KW, McCallum J, Sans N, Wenthold RJ (2000) PDZ domain suppression of an ER retention signal in NMDA receptor NR1 splice variants Neuron 28:887-898.

Tiffany AM, Manganas LN, Kim E, Hseuh YP, Sheng M, Trimmer JS (2000) PSD-95 and SAP97 exhibit distinct mechanisms for regulating $\mathrm{K}+$ channel surface expression and clustering. J Cell Biol 148:147-157.

Valtschanoff JG, Burette A, Davare MA, Leonard AS, Hell JW, Weinberg RJ (2000) SAP97 concentrates at the postsynaptic density in cerebral cortex. Eur J Neurosci 12:3605-3614.
Wenthold RJ, Yokotani N, Doi K, Wada K (1992) Immunochemical characterization of the non-NMDA glutamate receptor using subunitspecific antibodies. Evidence for a hetero-oligomeric structure in rat brain. J Biol Chem 267:501-507.

Wenthold RJ, Petralia RS, Blahos IIJ, Niedzielski AS (1996) Evidence for multiple AMPA receptor complexes in hippocampal CA1/CA2 neurons. J Neurosci 16:1982-1989.

Wyszynski M, Valtschanoff JG, Naisbitt S, Dunah AW, Kim E, Standaert DG, Weinberg R, Sheng M (1999) Association of AMPA receptors with a subset of glutamate receptor-interacting protein in vivo. J Neurosci 19:6528-6537.

Xia J, Zhang X, Staudinger J, Huganir RL (1999) Clustering of AMPA receptors by the synaptic PDZ domain-containing protein PICK1. Neuron 22:179-187. 